"Theory of mind"

\section{How to win wars and influence people} R Persaud

\section{World leaders need to consider listening to the medical profession to assist in the resolution of violent conflicts.}

D octors treat an ever increasing number of the casualties arising from violent conflicts around the world. ${ }^{1}$ Given prevention is inestimably better than cure, should the medical profession, besides patching up victims, also assist resolution of these conflicts, which are becoming the source of spiralling mortality and morbidity? ${ }^{2}$

After all, there is much that constitutes the experience and expertise of the medical world from which conflict resolution approaches could benefit; should our leaders listen to doctors more as they attempt to tackle mounting geo-political instability?

The neurobiology of violence is increasingly well understood and this knowledge could be of benefit to politicians wrestling with the problem-the brain's prefrontal cortex is now implicated in various forms of antisocial personality problems and intriguingly, it is also implicated in understanding other's mental states ${ }^{3}$ otherwise referred to as "theory of mind".

It has been suggested that our progress from non-human primate to Homo sapiens rests in our capacity to understand others' subjective experience. ${ }^{4}$ Assuming that others have minds worth trying to understand enables us to work together.

Psychiatrists argue we need ourselves to have a viable "theory of mind", to enter the violent person's subjective world, not just in order to be able to offer treatment, but also to anticipate the nature of the risks they pose to society. ${ }^{5}$ To explain is not to exonerate, but understanding is the first step in the prevention of violence. Scientific medicine is founded on this principle-to understand before acting and to base all action on insight - how much current action on the international stage reflects these principles, or is instead based on condemning our enemies without any coherent attempt to understand them?

Individuals poor at recognising mental states in others through facial expressions or vocal tones may not fully acquire "theory of mind" and thus inhibit their natural violence ${ }^{6}$; we dismiss such individuals as "psychopaths", to create the maximum distance between "them" and "us" but by this reckoning "psychopathy" would seem to be endemic among our leaders.

But it's not just neurobiology that can offer novel approaches to intractable disputes, but also the various therapies doctors use on a daily basis.

A characteristic of current global conflicts is that they are often a contagion of disputes that originated between communities that live in close proximity to each other, but share a mutual loathing. Some of the most longstanding animosities flourish when two groups divided along racial, political, or religious lines endure proximal to each other, and are therefore readily and impulsively able to inflict mutual damage. Northern Ireland, Sri Lanka, India/Pakistan, Southern Africa, and now the Middle East are all really examples of neighbours who violently coexist.

The fact that two murderous communities are locked into the same space and if left alone would produce mutually assured destruction, naturally leads to an application of techniques borrowed from marital therapy. Yet one side in the Palestinian/Israeli dispute is building a wall to separate themselves symbolically and so achieve a kind of divorce, showing clearly the dearth in alternative approaches to help the two sides coexist.

The restorative justice approaches now so currently in vogue as a tool of what has become known as "peacebuilding" borrow freely from these therapeutic models in resolving conflict. The idea being that using criminal or enforced justice perspectives to try and right wrongs is simply too slow, or in fact just plainly impossible when hundreds or thousands are implicated in human rights abuses on both sides.

Instead, the healing benefits of catharsis and ventilation are advocated and the restorative effects of being listened to are advocated as part of the power of giving testimony.

Thought of as a process, restorative justice brings together all the parties affected by an incident of wrongdoing, to decide collectively on a consensual basis how to deal with the aftermath of an incident. Offenders and their supporters assume responsibility for dealing with the aftermath of an offence using a deliberative process convened by a third party.

Recent research funded by the Medical Research Council of South Africa and conducted by the Department of Psychiatry at the University of Stellenbosch investigated survivors of human rights abuses in Southern Africa participating in the Truth and Reconciliation Commission (TRC). ${ }^{7}$ They found those who exhibited "low forgiveness" were significantly more likely to suffer poorer psychiatric health. They also found extremely high rates of psychiatric disorder in the survivors of human rights abuses with $63 \%$ of the sample achieving a formal psychiatric diagnosis.

The TRC's final report states that the process of giving testimony served a therapeutic function and highlighted cases of victims who forgave perpetrators. ${ }^{7}$ The prevalence of deep psychological disturbance as a produce of systematic and long running human rights abuses, as uncovered in this and other studies, speaks to the urgent need to address psychiatric as well as the medical casualties, if the cycles of violence are to be braked.

At their heart, restorative justice is about the family and group therapy idea that more conventional criminal justice approaches merely ensure legal and political professionals "steal" a conflict away from those directly affected, namely victims, offenders, and their local communities.

When two communities are deadlocked they need to "own" the conflict, and therefore understand how essential is the choice of resolution and moving on, rather than mutually assured destruction. What we increasingly see on the worldwide stage is third parties attempting to intervene to resolve disputes, but somehow exacerbating rather than resolving them.

Psychiatrists involved in family and marital therapy work delicately and subtly to encourage warring parties to discover their own motivation for learning to collaborate. What all patients really need in the longest run is to be assisted by a judicious profession in taking back responsibility for their own health.

As our leaders find increasingly around the world the body politic is taking a turn for the worse, they might in myriads of different ways, need to consider listening to their doctors more. Postgrad Med J 2005;81:115-1 16. doi: 10.1136/pgmj.2004.029934

Correspondence to: Dr R Persaud, Consultant Psychiatrist and Gresham Professor For Public 
Understanding Of Psychiatry, The Maudsley Hospital, Westways Clinic, 49 St James Road, Croydon CR9 2RR, UK; r.persaud@iop.kcl.ac. uk

\section{REFERENCES}

1 Levy BS, Sidel VW, eds. War and public health. New York: Oxford University Press, 1999.
2 Alexander DA, Klein S. Biochemical terrorism: too awful to contemplate, too serious to ignore: subjective literature review. $\mathrm{Br} J$ Psychiatry 2003;183:491-7.

3 Fuster JM. The prefrontal cortex: anatomy, physiology, and neuropsychology of the frontal lobe. 3rd ed. New York: Lippincott-Raven, 1997.

4 Baron-Cohen S, Tager-Flugsberg H, Cohen DJ. Understanding other minds: perspectives from autism. New York: Oxford University Press, 1993.
5 Fonagy $\mathrm{P}$ Towards a developmental understanding of violence. Br J Psychiatry 2003;183:190-2.

6 Blair RJR, Jones L, Clark F. The psychopathic individual: a lack of responsiveness to distress cues? Psychophysiology 1997;34:192-8.

7 Kaminer D, Stein DJ, Mbanga I, et al. The Truth and Reconciliation Commission in South Africa: relation to psychiatric status and forgiveness among survivors of human rights abuses. BrJ Psychiatry 2001;178:373-7.

\section{FILLER}

\section{Examination techniques}

ome exam techniques are clinically useful. Some are just exam techniques. Sadly, both can earn marks in this unfair world.

\section{Clinically useful exam techniques}

Differentiation between mitral systolic and diastolic murmurs is easy. "Feel the carotid." But it is difficult to correlate what you feel with what you hear, especially when anxious. It is easier to use movement of the stethoscope at the apex. Murmurs when the stethoscope is seen or felt to be pushed outwards are systolic, and murmurs when the stethoscope is returning are diastolic.

Identifying whether a murmur is louder during inspiration is easy. Correlate what you see with what you hear. But it is easier to do one thing at a time. Close your eyes while listening, get in rhythm with the murmur, and open your eyes to see if the patient is breathing in or out at the time of loudness.

\section{Just exam techniques}

Hold the stethoscope by squeezing the stethoscope waist (between the diaphragm and bell) between the ends of you index and middle fingers with the tube passing beneath your palm. This looks far more professional than plonking the stethoscope on the chest by holding it between the tips of your thumb, index and middle fingers.

"Place your left hand beneath the spleen and lifting it forward makes it easier to feel the spleen with your right finger tips" It does encourage the feeling that you are trapping the spleen and it does prevent you from falling to your right (every action has an opposite reaction). But does anyone believe that you can move the spleen forward in this way?

What do you say when you have no idea whether there is a palpable intra-abdominal organ such as a spleen? Say "There is equivocal splenomegaly." That is a definitive statement of the organ involved and a definitive statement of its palpability. Scientific and rigorous. Full marks!

You have presented you cardiac findings and the examiner asks "What about the diastolic murmur?", which you had not heard. Answer "It was difficult to hear." This suggests that you had heard it and also congratulates the examiner because he or she had heard it. It helps if you smile while replying thus- the examiner might be testing you and there might not be a diastolic murmur at all!

P D Welsby 